\title{
Monitoring Suhu pada Infant Warmer Menggunakan INCU Analyzer Berbasis Arduino
}

\author{
Diah Rahayu Ningtias ${ }^{1}$, Bayu Wahyudi²), dan Imam Tri Harsoyo ${ }^{3)}$ \\ 1), 2), 3) Program Studi Elektro Medik, Akademi Teknik Elektro Medik Semarang \\ 1), 2), 3) Jl. Kolonel Warsito Sugiarto, 172 Km. 2,5 Gunungpati Kota Semarang \\ e-mail:diahrahayu@atemsemarang.ac.id ${ }^{1)}$, bayuwahyudi@atemsemarang.ac.id ${ }^{2}$, imamtriharsoyo@atemsemarang.ac.id ${ }^{3)}$
}

\begin{abstract}
Temperature is the most important parameter in monitoring Infant Warmer medical equipment. In this study, temperature monitoring was carried out on the Lullaby GE Infant Warmer using INCU based on Arduino Uno. The temperature setting used was $34^{\circ} \mathrm{C}, 35^{\circ} \mathrm{C}, 36^{\circ} \mathrm{C}$ and $37^{\circ} \mathrm{C}$ with each setting repeated 3 times. The temperature sensor used in the INCU analyzer for T1 to T4 is DS18B20, while the T5 uses a DHT22 temperature sensor. At the Infant Warmer temperature, a low error value was obtained for all temperature settings, namely a temperature of $34^{\circ} \mathrm{C}$ with an error of 0.02 , a temperature of $35^{\circ} \mathrm{C}$ with an error of 0.03, a temperature of $36^{\circ} \mathrm{C}$ with an error of 0.004 and a temperature of $37^{\circ} \mathrm{C}$ with an error of 0. The INCU analyzer output low temperature is at T5, with temperature settings of $34^{\circ} \mathrm{C}, 35^{\circ} \mathrm{C}, 35^{\circ} \mathrm{C}$ and $37^{\circ} \mathrm{C}$ respectively 0.009, 0.07, 0.11 and 0.28. While the error value on $T 1$ to T4 ranges from 0.37, namely at T3 for a temperature setting of 35 ${ }^{\circ} \mathrm{C}$ to 0.84 , namely at $\mathrm{T3}$ for a setting of $37^{\circ} \mathrm{C}$. It can be concluded that the INCU analyzer that has a high degree of accuracy is the T5 using the DHT22 temperature sensor.
\end{abstract}

Keywords: Temperature, Infant Warmer, INCU Analyzer, Monitoring

\section{ABSTRAK}

Suhu merupakan parameter yang paling penting dalam kegiatan monitoring peralatan kesehatan Infant Warmer. Pada penelitian ini dilakukan monitoring suhu pada Infant Warmer merk GE tipe Lullaby menggunakan INCU berbasis Arduino Uno. Setting suhu yang digunakan adalah $34^{\circ} \mathrm{C}, 35^{\circ} \mathrm{C}, 36^{\circ} \mathrm{C}$ dan $37^{\circ} \mathrm{C}$ dengan masing - masing setting dilakukan pengulangan sebanyak 3 kali. Sensor suhu yang digunakan pada INCU analyzer untuk T1 sampai dengan T4 adalah DS18B20, sementara pada T5 menggunakan sensor suhu DHT22. Pada suhu Infant Warmer didapatkan nilai error rendah untuk semua setting suhu, yaitu suhu $34^{\circ} \mathrm{C}$ dengan error 0.02 , suhu $35^{\circ} \mathrm{C}$ dengan error 0.03 , suhu $36^{\circ} \mathrm{C}$ dengan error 0.004 dan suhu $37^{\circ} \mathrm{C}$ dengan error 0 . Sementara nilai error paling rendah keluaran suhu INCU analyzer adalah pada T5, dengan setting suhu $34^{\circ} \mathrm{C}, 35^{\circ} \mathrm{C}, 35^{\circ} \mathrm{C}$ dan $37^{\circ} \mathrm{C}$ secara berturut turut adalah $0.009,0.07,0.11$ dan 0.28 . Sementara nilai error pada T1 sampai dengan T4 berkisar antara 0.37 yaitu pada $\mathrm{T} 3$ untuk setting suhu $35^{\circ} \mathrm{C}$ sampai dengan 0.84 yaitu pada $\mathrm{T} 3$ untuk setting $37^{\circ} \mathrm{C}$. Dapat disimpulkan bahwa pada INCU analyzer yang memiliki tingkat akurasi tinggi adalah T5 dengan menggunakan sensor suhu DHT22.

Kata Kunci: Suhu, Infant Warmer, INCU Analyzer, Monitoring

\section{Pendahuluan}

nfant Warmer merupakan peralatan kesehatan

$I$ yang difungsikan sebagai tempat perlindungan bayi bagi yang baru lahir. Infant warmer juga sebagai tempat singgah sementara untuk menstabilkan suhu tubuh bayi yang lahir mengalami hipotermia. Dengan adanya panas (penghangat) yang dihasilkan oleh infant warmer, maka bayi yang lahir tidak normal dikarenakan suhu tubuh yang kurang stabil dapat dikondisikan sesuai kebutuhan. Jika suhu bayi sudah stabil dan normal, maka bayi akan dipindahkan ke bed biasa [1].

Komponen utama dari infant warmer yaitu heater dan kontrol suhu. Penghangat pada infant warmer menggunakan elemen kering yang diletakkan diatas bayi yang suhunya dapat diatur sesuai kebutuhan. Radiasi panas yang mengenai bayi suhunya antara $35^{\circ} \mathrm{C}-$ $37^{\circ} \mathrm{C}$. Pada kontrol suhu juga terdapat sensor yang diletakkan pada bed bayi yang berfungsi menyensor suhu tubuh bayi. Sensor ini juga berfungsi mengontrol kerja heater agar tidak terjadi over heat [2].
Umumnya, suhu tubuh normal orang dewasa adalah $37^{\circ} \mathrm{C}$. Namun, hal ini berbeda dengan kondisi bayi. Sebab, suhu tubuh normal bayi adalah antara $36,4^{\circ} \mathrm{C}$ sampai dengan $37,5^{\circ} \mathrm{C}$. Pada suhu ini, tubuh Si Kecil bekerja secara normal meski tubuhnya sedikit terasa hangat. American Association of Pediatrics (AAP) menyebutkan bahwa bayi cenderung memiliki suhu yang lebih tinggi daripada anak yang lebih tua. Suhu setiap orang pun akan berbeda, di mana paling tinggi adalah antara siang dan sore hari, sedangkan yang paling rendah antara tengah malam dan pagi hari [3].

Kegiatan monitoring suhu pada Infant Warmer merupakan hal yang sangat penting, hal ini dikarenakan suhu merupakan parameter utama pada Infant Warmer. Berdasarkan Peraturan Menteri Kesehatan Republik Indonesia (Permenkes RI), kegiatan monitoring suhu pada Infant Warmer disebut juga dengan kalibrasi [4].

Kalibrator yang digunakan untuk mengkalibrasi (memonitoring) suhu Infant Warmer adalah INCU (Incubator Analyzer). Pada INCU, selain dapat digunakan untuk memonitoring Infant Warmer, dapat juga digunakan untuk mengkalibrasi Baby Incubator [5]. 
Tujuan penelitian ini adalah melakukan monitoring suhu pada Infant Warmer dengan menggunakan INCU berbasis Arduino Uno yang telah dibuat. Luaran yang didapatkan adalah mengetahui suhu mengetahui akurasi setting suhu yang dihasilkan oleh INCU yang telah dibuat.

\section{Metode Penelitian}

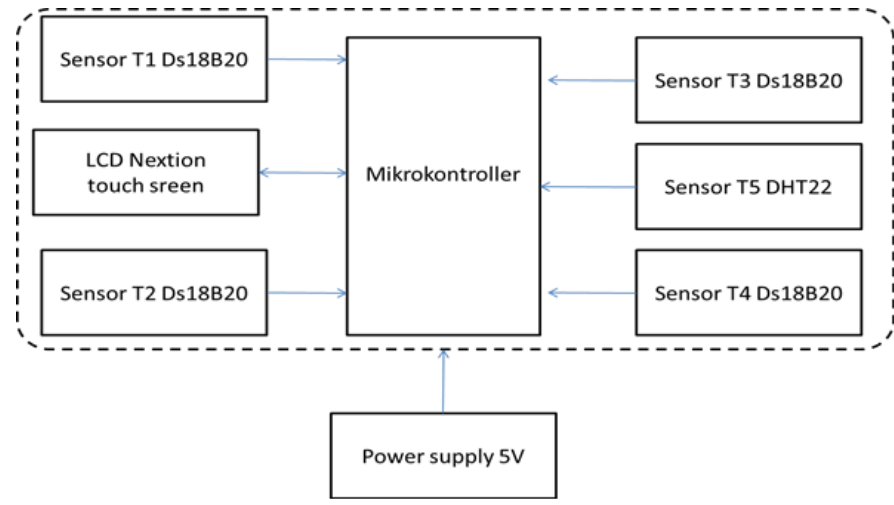

Gambar 1. Blok diagram INCU Analyzer berbasis Arduino UNO

Penelitian ini dilakukan di Laboratorium Akademi Teknik Elektro Medik Semarang menggunakan Infant Warmer merk GE tipe Lullaby. Blok diagram INCU Analyzer berbasis Arduino Uno yang dibuat seperti pada Gambar 1. INCU Analyzer yang dibuat menggunakan sensor suhu DS18B20 untuk T1, T2, T3 dan T4. Sedangkan untuk T5 menggunakan sensor suhu DHT22. T1 sampai dengan T4 dapat dilepas dan ketika pengambilan data posisinya diletakkan pada ujung matras Infant Warmer. Sedangkan pada T5, sensornya terletak pada badan INCU sehingga bersifat tetap (tidak dapat dipindahkan).

Sensor suhu DS18B20 merupakan sensor suhu dengan akurasi tinggi dan nilai eror kecil, selain itu juga bersifat anti air (waterproof). Sensor DS18B20 juga dapat dikombinasikan menggunakan platform Arduino dan memiliki harga yang terjangkau. Selain dapat digunakan pada kegiatan kalibrasi Infant Warmer, sensor ini juga memiliki rata-rata rentang kesalahan kecil yaitu $3^{\circ} \mathrm{C}-4^{\circ} \mathrm{C}$ sehingga dapat juga digunakan untuk kegiatan kalibrasi pada Baby Incubator. Dengan demikian dapat menekan biaya pembuatan INCU, karena lebih efisien [6]. Rentang suhu operasional pada DS18B20 ini yaitu $-55^{\circ} \mathrm{C}$ sampai dengan $+125^{\circ} \mathrm{C}$ dengan kesalahan $\pm 0,5^{\circ} \mathrm{C}$ pada $-10^{\circ} \mathrm{C}$ hingga $+85^{\circ} \mathrm{C}$ dan memiliki suhu $0,0625^{\circ} \mathrm{C}$. Skala linier tegangan dan suhu sensor adalah $+10.0 \mathrm{mV} /{ }^{\circ} \mathrm{C}$ [7].

T5 pada INCU Analyzer menggunakan sensor DHT22 untuk digunakan data kelembabannya pada kalibrasi Baby Incubator. Namun pada penelitian ini, dengan menggunakan sensor DHT22 diambil pula data suhu untuk monitoring Infant Warmer. Sensor DHT22 merupakan sensor suhu dan kelembaban yang murah, selain itu juga memiliki akurasi yang tinggi. Tegangan input untuk sensor DHT22 adalah 3,3-5,5V DC. Memiliki sistem one wire bus, yaitu hanya ada satu jalur untuk beberapa sensor. Untuk operasi nilai kelembaban yaitu $0-100 \%$ dengan rentang suhu -40 sampai dengan $80^{\circ} \mathrm{C}$. Akurasi kelembaban $\pm 2 \%$ dan maksimal $\pm 5 \%$ [8].

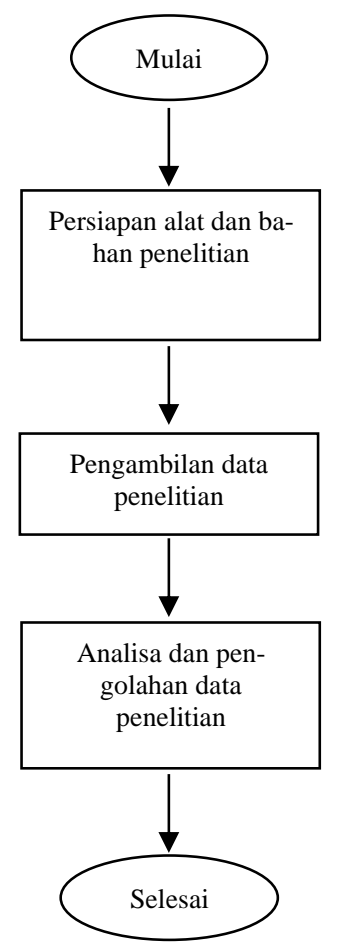

Gambar 2. Diagram alir penelitian

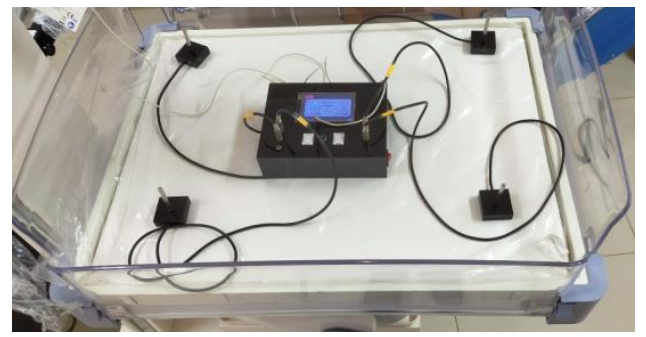

Gambar 3. Monitoring suhu menggunakan INCU Analyzer

Pengambilan data menggunakan INCU Analyzer berbasis arduino yang telah dibuat dengan rentang variasi suhu yaitu $34^{\circ} \mathrm{C}, 35^{\circ} \mathrm{C}, 36^{\circ} \mathrm{C}$ dan $37^{\circ} \mathrm{C}$. Pada masingmasing variasi suhu tersebut dilakukan pengulangan sebanyak 3 kali. Variasi yang dilakukan berdasarkan suhu tubuh normal bayi baru lahir yaitu pada rentang $35,5^{\circ} \mathrm{C}$ sampai dengan $36,5^{\circ} \mathrm{C}$ [9]. Jarak antara INCU dengan pemanas pada Infant Warmer adalah $70 \mathrm{~cm}$. Pada INCU Analyzer berbasis arduino yang dibuat, dipilih mode Infant Warmer. Kemudian pilih setting suhu pada Infant Warmer yaitu $34^{\circ} \mathrm{C}$, kemudian ditunggu hingga suhu tertampil yaitu $34^{\circ} \mathrm{C}$. Setelah mencapai suhu setting, ditunggu waktunya selama 5 menit, hal ini dilakukan untuk melihat kestabilan data yang didapatkan. Selanjutnya diulangi untuk setting suhu 35, 36 dan $37^{\circ} \mathrm{C}$ kemudian data yang didapatkan dianalisa menggunakan Microsoft Excel. 


\section{HASIL DAN PEMBAHASAN}

Data yang dihasilkan adalah nilai error yang diambil dari keluaran suhu pada Infant Warmer dan INCU Analyzer. Sebelum diketahui nilai error, terlebih dahulu mencari nilai standar deviasi untuk keluaran suhu tersebut. Dengan mengetahui nilai error, maka diketahui pula akurasi pada keluaran suhu tersebut. Data hasil pengamatan untuk monitoring suhu pada Infant Warmer menggunakan INCU Analyzer berbasis Arduino Uno
Setelah dilakukan pengambilan data monitoring suhu pada Infant Warmer menggunakan INCU Analyzer berbasis Arduino Uno, selanjutnya didapatkan data nilai error untuk masing-masing setting suhu. Berdasarkan Tabel 2, diketahui bahwa nilai error paling tinggi didapatkan pada nilai keluaran suhu INCU Analyzer untuk T1 sampai dengan T4. Sementara pada T5 memiliki nilai error paling rendah.

Tabel 2. Standar deviasi dan nilai error keluaran suhu.

\begin{tabular}{|c|c|c|c|c|c|c|c|c|c|c|c|c|c|}
\hline \multirow{2}{*}{ No } & \multirow{2}{*}{$\begin{array}{l}\text { Setting } \\
\text { Suhu } \\
\left({ }^{\circ} \mathrm{C}\right)\end{array}$} & \multirow{2}{*}{$\begin{array}{c}\text { Standar } \\
\text { Deviasi Infant } \\
\text { Warmer }\end{array}$} & \multicolumn{5}{|c|}{ Standar Deviasi INCU Analyzer } & \multirow{2}{*}{$\begin{array}{l}\text { Error } \\
\text { Infant } \\
\text { Warmer }\end{array}$} & \multicolumn{5}{|c|}{ Error INCU Analyzer } \\
\hline & & & $\mathrm{T} 1$ & $\mathrm{~T} 2$ & $\mathrm{~T} 3$ & $\mathrm{~T} 4$ & T5 & & $\mathrm{T} 1$ & $\mathrm{~T} 2$ & $\mathrm{~T} 3$ & $\mathrm{~T} 4$ & $\mathrm{~T} 5$ \\
\hline 1 & 34 & 0.04 & 0.98 & 1.06 & 1.14 & 1.08 & 0.02 & 0.02 & 0.57 & 0.61 & 0.66 & 0.62 & 0.009 \\
\hline 2 & 35 & 0.05 & 1.10 & 1.18 & 0.64 & 1.20 & 0.13 & 0.03 & 0.64 & 0.68 & 0.37 & 0.70 & 0.07 \\
\hline 3 & 36 & 0.01 & 1.20 & 1.30 & 1.42 & 1.29 & 0.20 & 0.004 & 0.70 & 0.75 & 0.81 & 0.74 & 0.11 \\
\hline 4 & 37 & 0 & 1.24 & 1.41 & 1.45 & 1.41 & 0.48 & 0 & 0.72 & 0.81 & 0.84 & 0.81 & 0.28 \\
\hline
\end{tabular}

dapat dilihat pada Tabel 1. Pada tabel disajikan pengambilan data dengan variasi setting suhu Infant Warmer yaitu $34^{\circ} \mathrm{C}, 35^{\circ} \mathrm{C}, 36^{\circ} \mathrm{C}$ dan $37^{\circ} \mathrm{C}$. Hasil keluaran suhu pada Infant Warmer memiliki akurasi tinggi untuk semua setting suhu, dikarenakan tidak melebihi batas toleransi yaitu $\pm 5 \%$ [10]. Hal ini juga terlihat pada data keluaran suhu T5 INCU Analyzer yang menggunakan sensor DHT22 untuk setting suhu $34^{\circ} \mathrm{C}$ sampai dengan $36^{\circ} \mathrm{C}$, namun pada setting suhu $37^{\circ} \mathrm{C}$ memiliki rata-rata pengambilan data melebihi toleransi $\pm 5 \%$ yaitu $38.93^{\circ} \mathrm{C}$.

Pada nilai keluaran suhu INCU Analyzer T1 sampai dengan T4 yang menggunakan sensor suhu DS18B20 didapatkan hasil semuanya di luar batas toleransi $\pm 5 \%$. Dengan demikian dapat diketahui bahwa sensor DHT22 memiliki nilai keakuratan yang lebih tinggi dibandingkan dengan sensor suhu DS18B20. Namun untuk mengetahui lebih lanjut terkait spesifikasi maupun karakteristik dari masing-masing sensor suhu masih perlu dilakukan penelitian lebih lanjut.

\begin{tabular}{|c|c|c|c|c|c|c|}
\hline \multirow{2}{*}{$\begin{array}{l}\text { Setting } \\
\text { Suhu } \\
\left({ }^{\circ} \mathbf{C}\right)\end{array}$} & \multirow{2}{*}{$\begin{array}{c}\text { Suhu } \\
\text { Infant } \\
\text { Warmer } \\
\left({ }^{\circ} \mathrm{C}\right)\end{array}$} & \multicolumn{5}{|c|}{ Suhu INCU Analyzer $\left({ }^{\circ} \mathbf{C}\right)$} \\
\hline & & T1 & $\mathbf{T} 2$ & T3 & T4 & T5 \\
\hline \multirow{3}{*}{34} & 34.1 & 30.25 & 29.63 & 29.56 & 29.63 & 34.00 \\
\hline & 34.4 & 30.00 & 30.00 & 29.56 & 29.81 & 34.20 \\
\hline & 34 & 29.94 & 29.63 & 29.19 & 29.63 & 34.00 \\
\hline \multirow[t]{2}{*}{$\begin{array}{l}\text { Rata } \\
\text { Rata }\end{array}$} & 34.17 & 30.06 & 29.75 & 29.44 & 29.69 & 34.07 \\
\hline & 34 & 30.65 & 30.19 & 30.50 & 30.25 & 35.30 \\
\hline \multirow[t]{2}{*}{35} & 35.2 & 30.50 & 30.38 & 36.13 & 30.13 & 35.60 \\
\hline & 35.2 & 30.63 & 30.25 & 30.69 & 30.25 & 35.60 \\
\hline \multirow[t]{2}{*}{$\begin{array}{l}\text { Rata } \\
\text { Rata }\end{array}$} & 34.80 & 30.59 & 30.27 & 32.44 & 30.21 & 35.50 \\
\hline & 36.3 & 31.56 & 30.88 & 30.38 & 31.06 & 37.10 \\
\hline \multirow[t]{2}{*}{36} & 35.7 & 31.38 & 30.88 & 30.63 & 30.94 & 36.60 \\
\hline & 35.9 & 30.63 & 30.63 & 30.00 & 30.56 & 36.70 \\
\hline \multirow[t]{2}{*}{$\begin{array}{l}\text { Rata } \\
\text { Rata }\end{array}$} & 35.97 & 31.19 & 30.80 & 30.34 & 30.85 & 36.80 \\
\hline & 37 & 32.06 & 31.25 & 30.50 & 31.25 & 38.40 \\
\hline \multirow[t]{2}{*}{37} & 37.1 & 32.19 & 31.44 & 31.44 & 31.44 & 39.30 \\
\hline & 36.9 & 31.88 & 31.38 & 31.63 & 31.44 & 39.10 \\
\hline $\begin{array}{l}\text { Rata } \\
\text { Rata }\end{array}$ & 37.00 & 32.04 & 31.36 & 31.19 & 31.38 & 38.93 \\
\hline
\end{tabular}

\section{KESIMPULAN}

Berdasarkan data hasil pengamatan, sensor suhu yang digunakan memiliki akurasi yang berbeda. Pada suhu Infant Warmer didapatkan nilai error rendah untuk semua setting suhu, yaitu suhu $34^{\circ} \mathrm{C}$ dengan error 0.02 , suhu $35^{\circ} \mathrm{C}$ dengan error 0.03 , suhu $36^{\circ} \mathrm{C}$ dengan error 0.004 dan suhu $37^{\circ} \mathrm{C}$ dengan error 0 . Sementara nilai error paling rendah keluaran suhu INCU analyzer adalah pada T5 yang menggunakan sensor suhu DHT22, dengan setting suhu $34^{\circ} \mathrm{C}, 35^{\circ} \mathrm{C}, 35^{\circ} \mathrm{C}$ dan $37^{\circ} \mathrm{C}$ secara berturut turut adalah $0.009,0.07,0.11$ dan 0.28. Sementara nilai error pada $\mathrm{T} 1$ sampai dengan T4 berkisar antara 0.37 yaitu pada $\mathrm{T} 3$ untuk setting suhu $35^{\circ} \mathrm{C}$ sampai dengan 0.84 yaitu pada $\mathrm{T} 3$ untuk setting $37^{\circ} \mathrm{C}$. Dapat disimpulkan bahwa pada INCU analyzer yang memiliki tingkat akurasi tinggi adalah T5 dengan menggunakan sensor suhu DHT22.

\section{DAFTAR PUStaka}

[1] S. Muharom, I. Masfufiah, R. A. Firmansyah, A. Hamid, and S. Utomo, "Implementasi Kontrol Suhu Menggunakan Metode PID pada Aplikasi Inkubator Infant Warmers," Cyclotron, vol. 4, no. 1, pp. 55-59, 2021.

[2] M. S. A. Nampira and A. Kholiq, "A Modification of Infant Warmer with Monitoring of Oxygen Saturation, Heart Rate and Skin Temperature," J. Electron. Electromed. Med. Informatics, vol. 3, no. 1, pp. 1-6, 2021.

[3] P. V. Fridely, "Pentingnya Melakukan Pengukuran Suhu pada Bayi Baru Lahir untuk Mengurangi Angka Kejadian Hipotermi," J. Ilm. Bidan, vol. 2, no. 2, pp. 912, 2016.

[4] Permenkes, "No Title," in Peraturan Menteri Kesehatan Republik Indonesia Tentang Pengujian dan Kalibrasi Alat Kesehatan, 2015.

[5] L. Nurrohmah, D. H. Andayani, and A. Pudji, "Development of Incubator Analyzer Using Personal Computer Equiped With Measurement Certificate," J. Electron. Electromed. Med. Informatics, vol. 2, no. 2, pp. 74-79, 2020.

[6] M. A. Pertijs, A. A. L, M. K. A.A, and H. J. H, "LowCost Calibration Techniques for Smart Temperature 
Sensors," IEEE Sens. J., vol. 10, no. 6, pp. 1098-1105, 2010, doi: 10.1109/JSEN.2010.2040730.

[7] R. A. Koestoer, Y. A. Saleh, and I. Roihan, “A simple method for calibration of temperature sensor DS18B20 waterproof in oil bath based on Arduino data acquisition system A Simple Method for Calibration of Temperature Sensor DS18B20 Waterproof in Oil Bath Based on Arduino Data Acquisition System," vol. 020006, 2019.

[8] P. M. Korake and M. K. Bhanarkar, "Humidity and Temperature Measurement WSN node for Grapes Environmental Condition Monitoring," vol. 2, no. 5, pp. 7276, 2015.

[9] I. R. Puspita, R. Suradi, and Z. Munasir, "Insidens dan Faktor Risiko Hipotermia Akibat Memandikan pada Bayi Baru Lahir Cukup Bulan," Sari Pediatr., vol. 8, no. 4, pp. 258-264, 2007.

[10] A. D. Pratiwi, E. Yulianto, and A. Kholiq, "Infant Incubator Berbasis Proportional Integral dan Derivative (PID) Dilengkapi Dengan Mode Kanguru," Teknokes, vol. 12, no. 1, pp. 33-38, 2019, doi: 10.35882/teknokes.v12i1.6. 